\title{
Field-specific difficulties for transplanted rice to cope with ammonia from a localized enriched environment
}

\author{
Rémi GAUDIN $^{1 *}$, Berthe RASOAMAMPIONONA ${ }^{2}$ and Lilia RABEHARISOA ${ }^{3}$ \\ ${ }^{1}$ Montpellier SupAgro, UMR System, 2 Place Viala, 34060 Montpellier, France. \\ ${ }^{2}$ Faculté des Sciences, Université d'Antananarivo, B.P. 906 Antananarivo 101, Madagascar. \\ ${ }^{3}$ Ecole Supérieure des Sciences Agronomiques, Université d'Antananarivo, B.P. 3383, Antananarivo 101, \\ Madagascar. \\ *Corresponding author; E-mail: remi.gaudin@supagro.fr
}

\begin{abstract}
The objective of the study was to find some relationship between the location of rice fields in a typical valley of central Madagascar and the response of transplanted rice to nitrogen fertilizer. Comparison was made between lowland locations and plain location. High rainfalls are typically occurring during the periods of soil puddling and rice transplantation. As a consequence, it is difficult to manage nitrogen fertilization of the crop. To avoid nitrogen losses by runoff, urea deep placement $(2 \mathrm{~g}$ urea-supergranules at $10 \mathrm{~cm}$ depth) was practiced. Probes attached to urea super-granules enabled to observe the dynamics of the ammonia derived from the fertilizer. These observations were performed in three fields (different location). The response of transplanted rice to nitrogen was weak in the lowlands, and rice performed badly in ammonia uptake. In the adjacent plain, the response was better and ammonia correctly assimilated. Ferrous ion toxicity and low phosphorus status are discussed as causes for the rice difficulty to benefit from an ammonia enriched environment in the lowland fields.
\end{abstract}

(C) 2016 International Formulae Group. All rights reserved.

Keywords: Lowland, urea super-granule, Madagascar, nutritional disorder, ferrous toxicity.

\section{INTRODUCTION}

Transplanted rice is the dominant crop in Madagascar, well before upland rice, cassava, yam, potato and corn. It is cultivated in alluvial plains and in numerous lowlands of the central highland. The alluvial plains are fertile and can even support two crops per year in favorable climate (Marovoay in the western part of the country). But the dominant region for rice cropping is the central high plateau. Under the pressure of the central kingdom regime (period of time spanning several centuries), farmers transformed the landscape of inland valleys, marshes and alluvial plains (Randrianja and Ellis, 2009) in order to obtain soil conditions suited for wetland rice cultivation. Field bunding is very ancient in contrast to its recent introduction in West African countries such as Ivory Coast (Touré et al., 2009). The mean yield of wetland rice is low, around $2 \mathrm{Mg}^{-h^{-1}}$ (Minten and Barrett, 2008). Most of the farmers grow biological rice because they have no access to fertilizers (or very limited access to 
fertilizers). Moreover, the island which has been at the origin of the "system of rice intensification" does not succeed in its development because the organic manure it requires (Tsujimoto et al., 2009) is not produced in sufficient quantity for large areas.

Principal constraints of the central high plateau are the rainfall regime as well as the location of the fields within valleys arranged as fingers in the landscape. Very intense and numerous rain events are observed between November and February. Water circulates directly (over the field bunds) from higher to lower fields of the lowlands impeding any control of the paddy soil humidity. It is collective adjustment of the floodwater level which enables wetland rice cultivation.

To insure food security in the future, the paddy yield has to rise. A seemingly easy solution should be the use of fertilizers by farmers. This investigation aimed at defining the response of transplanted rice to fertilizer in relation with the field situation in the landscape. The lowland situations were compared to the nearest alluvial plain situation.

\section{MATERIALS AND METHODS Agronomic practices}

Three sites of the Ambohitrakoho

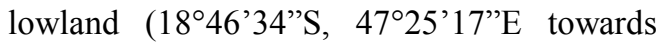
$\left.18^{\circ} 47^{\prime} \mathrm{S}, 47^{\circ} 26^{\prime} 06^{\prime \prime} \mathrm{E}\right)$ were chosen for the installation of a trial comparing the following NPK treatments: $0-0-0$ and 58-90-45. The site positions were selected according to the degree of wetness during the dry season (Figure 1): up and down positions totally or partly saturated (water table depth at less than $20 \mathrm{~cm}$ from the soil surface), and plain position with good drainage (water table descending 50 to $100 \mathrm{~cm}$ below the soil surface). The trial covered an area of $343 \mathrm{~m}^{2}$ (up position) or $365 \mathrm{~m}^{2}$, representing 49 and $63 \%$ of the field in the up and down positions, and only $15 \%$ of the field in the plain.

Wetland rice (local 1632 variety) was transplanted in $20 \mathrm{~cm} \times 20 \mathrm{~cm}$ geometry. Three seedlings (three weeks old) were used per hill. Transplanting was at the same date
(13 November) for the up and down situations; it occurred one month later for the plain situation because it takes a certain time for the first rains to deliver sufficient water to permit harrowing and puddling after the plowing operation that has taken place some weeks before. Harvest was practiced at 120 DAT (days after transplanting). In the fertilizer treatment, nitrogen was deep placed because it is the only way to avoid nitrogen loss through runoff during the rainy season in central Madagascar (Dupuy et al., 1990). N was applied at transplanting as $2 \mathrm{~g}$ urea supergranules (USG) placed by hand $10 \mathrm{~cm}$ deep between four hills. $\mathrm{P}$ was brought as hydroxy apatite and $\mathrm{K}$ as potassium chloride, mixed with the soil at the end of puddling operation. Each trial had four replications. The number of plots was 8 . Bunds $30 \mathrm{~cm}$ large separated the plots and enabled passage for soil solution sampling.

\section{Analytical measurements}

The disappearance of ammonia from deep placed USG was monitored by measuring the ammonia content of soil solution. This soil solution was drawn by vacuum action (manual pump) acting on small ceramic cup attached to USG, as described in Gaudin and Dupuy (1999). In this position, the disappearance of ammonia is driven first by diffusion then by root uptake, with a transition at around $10 \mathrm{mM}$ ammoniacal-N (Gaudin, 2012; Gaudin and D'Onofrio, 2015). The urea content of soil solution was also monitored in order to verify full urea hydrolysis. To this effect, a mean sample was built with the volumes left by ammonia determination. Urea and ammonia were determined by colorimetric methods, respectively diacetylmonoximthiosemicarbazide (Douglas and Bremner, 1970) and indophenol-blue (Novozamsky et al., 1974) methods.

\section{Statistical analysis}

An analysis of variance (ANOVA) was performed on the yield. The analysis was performed according to the procedure 
described in Little and Hills (1978). The test of Snedecor-Fisher was applied. The observed $\mathrm{F}$ value ( $\mathrm{F}$ for Fisher), defined as the ratio of the mean square of factor (position, fertilizer) to the mean square of error, was calculated and compared with the required $\mathrm{F}$ values for significance at the $5 \%$ and $1 \%$ probability levels.

\section{RESULTS}

\section{Grain yields}

The yield of control was 1.7 and 1.8 $\mathrm{Mg} \cdot \mathrm{ha}^{-1}$ in the lowland situation and 2.4 Mg.ha ${ }^{-1}$ in the plain. The fertilizer had a pronounced effect in the plain (Table 1) with an increase of $1.5 \mathrm{Mg} \mathrm{ha}^{-1}$ in paddy yield. The ANOVA indicates very significant effects of position and fertilizer with observed $\mathrm{F}$ larger than required $\mathrm{F}$ at the $1 \%$ probability level (Table 2).

\section{Urea hydrolysis}

The hydrolysis was rapid in the first few days. In the following weeks, residual urea-N was observed (Figure 2). In this respect, the three sites presented the same kinetics.

\section{Ammonia disappearance}

During six weeks, the kinetics of ammonia disappearance was in agreement with point-like positioning of ammonia and its spherical diffusion. The diffusion coefficient, calculated from the ammonia concentration in the plain situation $(0.2845 \mathrm{M}$ at $4 \mathrm{DAT})$ and assuming $0.6 \mathrm{~cm}^{3} \cdot \mathrm{cm}^{-3}$ porosity was 1.06 $\mathrm{cm}^{2} \cdot \mathrm{d}^{-1}$. This value is similar to ammonia nitrogen diffusion coefficient values obtained in other paddy fields of Madagascar.

Around 45 DAT and beyond, it was possible to draw a straight line to distinguish between kinetics of plain and lowland fields (Figure 2). Ammonia disappearance occurred quickly in the plain and with less rapidity (and with more heterogeneity) in the two lowland situations.

Table 1: Grain yield $\left(\mathrm{Mg} \cdot \mathrm{ha}^{-1}\right)$.

\begin{tabular}{lll}
\hline Position & $\begin{array}{l}\text { Control } \\
(\mathbf{N P K}=\mathbf{0 - 0 - 0})\end{array}$ & $\begin{array}{l}\text { USG }(\mathbf{N}=\mathbf{5 8}) \\
\text { with } \mathbf{P K}=\mathbf{9 0 - 4 5}\end{array}$ \\
\hline Up & 1.73 & 1.96 \\
Low & 1.81 & 2.10 \\
Plain & 2.38 & 3.94 \\
\hline
\end{tabular}

Table 2: Analysis of variance of yield with position and fertilizer treatments

\begin{tabular}{lllllll}
\hline $\begin{array}{l}\text { Source of } \\
\text { variation }\end{array}$ & $\begin{array}{l}\text { Degree of } \\
\text { freedom }\end{array}$ & $\begin{array}{l}\text { Sum of } \\
\text { squares }\end{array}$ & $\begin{array}{l}\text { Mean } \\
\text { square }\end{array}$ & $\begin{array}{l}\text { Observed } \\
\text { F }\end{array}$ & $\begin{array}{l}\text { Required F } \\
\mathbf{5 \%}\end{array}$ & $\mathbf{1 \%}$ \\
\hline Total & 23 & 15.050 & & & & \\
Position & 2 & 8.571 & 4.2855 & 23.71 & 3.49 & 5.85 \\
Fertilizer & 1 & 2.864 & 2.864 & 15.85 & 4.35 & 8.10 \\
Error & 20 & 3.615 & 0.18075 & & & \\
\hline
\end{tabular}




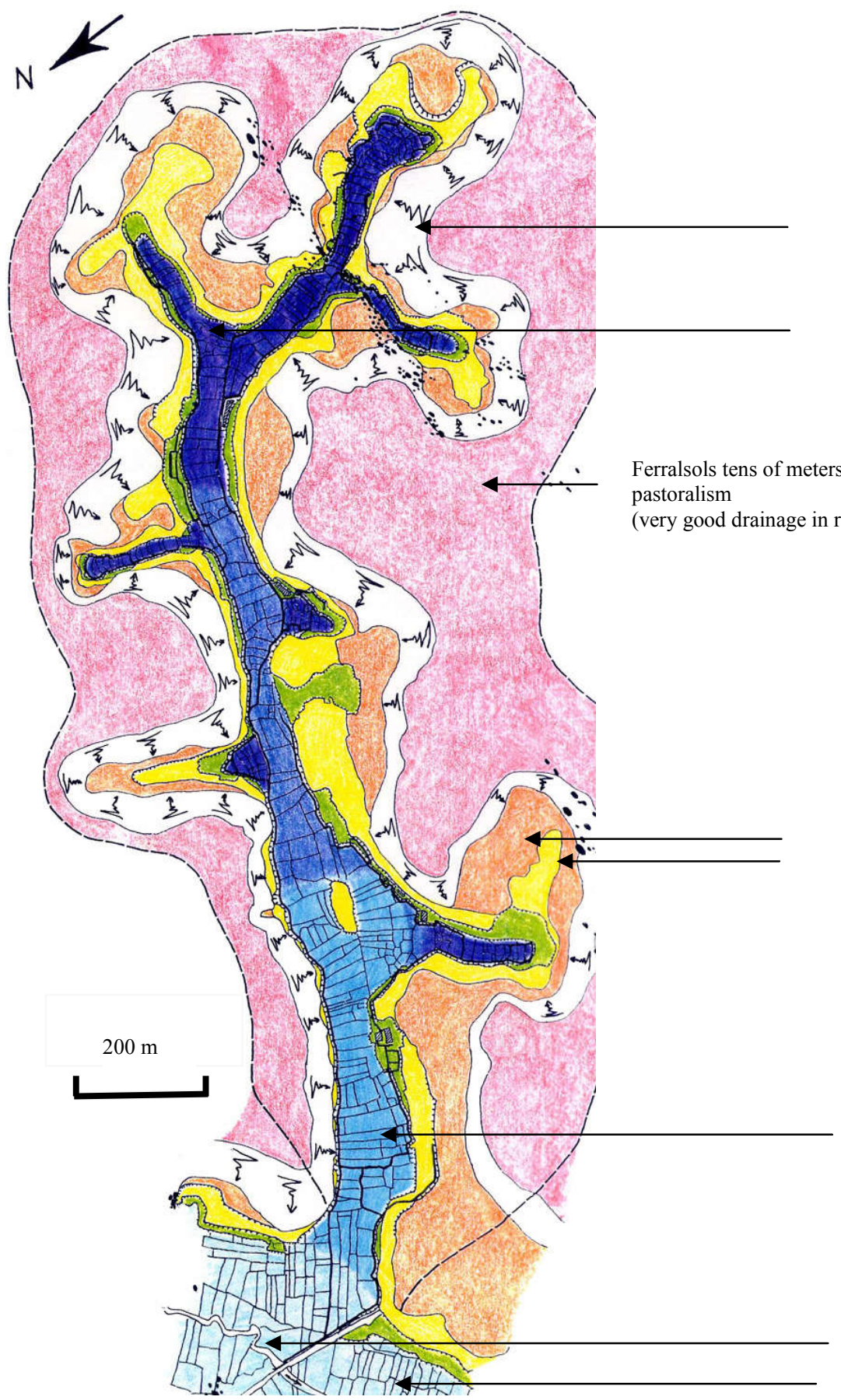

Intermediate area with convex slopes (no crop)

Up position

Flat areas

(upland crops)

\section{Low position}

\section{Andakana river \\ Plain position}

Figure 1: Map of the lowland of Ambohitrakoho with the three localizations (up, low and plain) of the trials led by the team of Antananarivo University. Shade of blue related to the degree of wetness in dry season (full blue for permanent saturation of the soil). The plain is extending several $\mathrm{km}$ to Mahitsy, receiving waters from a dozen lowlands. 


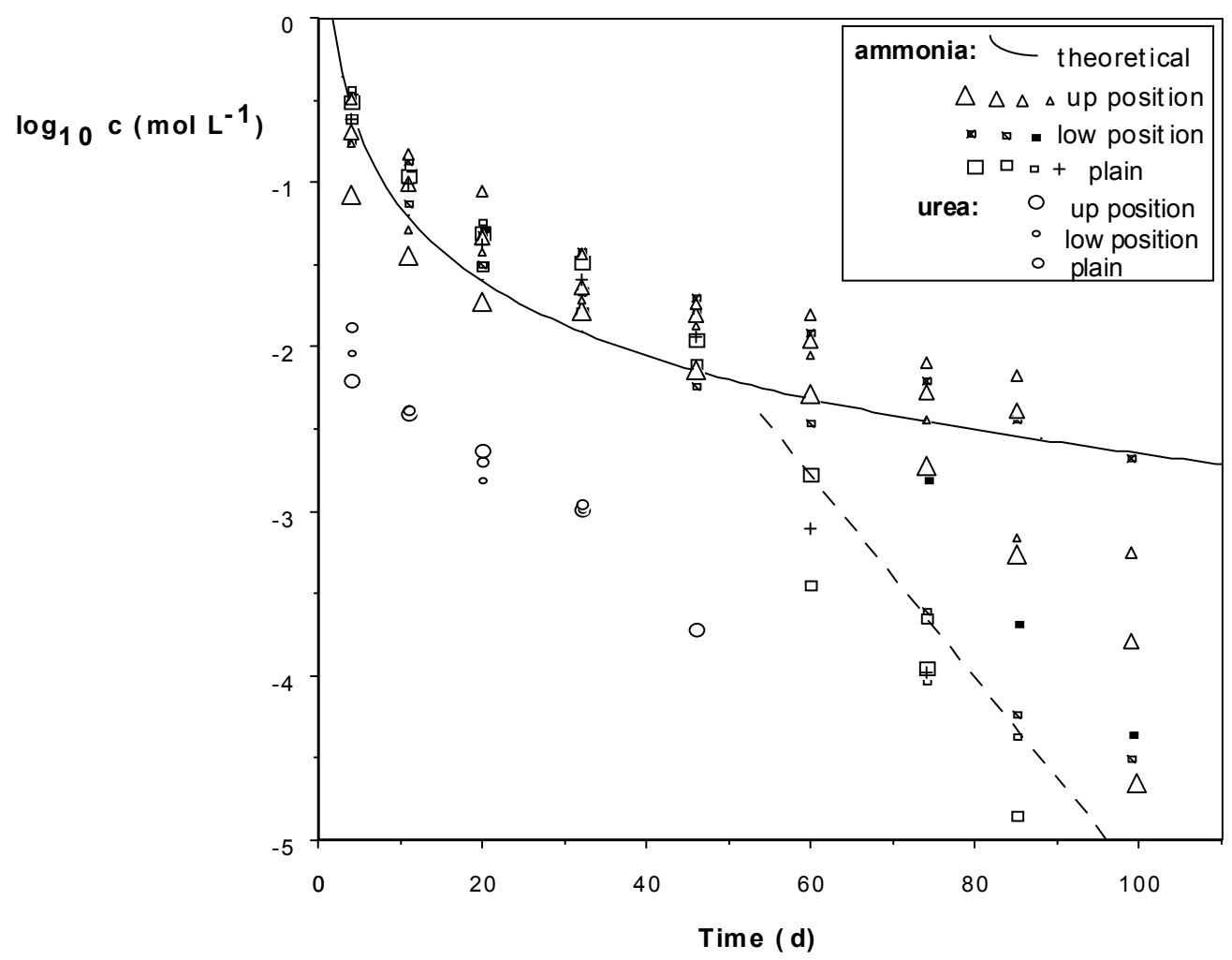

Figure 2: Time-course of ammonia-N and urea-N concentrations at the placement sites of $2 \mathrm{~g}$ USG for three field positions: up, down and plain. The theoretical curve is for an un-transplanted situation with a diffusion coefficient for ammonia at $1.06 \mathrm{~cm}^{2} \mathrm{~d}^{-1}$. The broken line separates data in the up and down situations (points above the line) from data in plain situation (points below the line).

\section{DISCUSSION}

Rice soils of the highlands are derived mostly from highly weathered ferrallitic clay and peat materials. Important constraints are low available soil $\mathrm{P}$ and/or high $\mathrm{P}$ fixation, $\mathrm{N}$ deficit in mineral soils, slow organic matter decomposition and poor nutrient uptake due to low temperature, and iron toxicity (Balasubramanian et al., 1995). In the present case, no evident symptom of iron toxicity such as bronzing was found.

Iron toxicity is a complex phenomenon (Becker and Asch, 2005) and it is plausible that differences in the hydrological regime between fields can be sufficiently important as to interfere with this phenomenon. In an inland valley of Ivory Coast, Touré et al. (2010) has observed difference of rice yields in relation with field hydrological regime and position. The hydrological regime is clearly identified by Fageria et al. (2008) as one factor on which the rice grower can intervene to limit the occurrence of iron toxicity: good drainage enables elimination of part of the ferrous iron and transformations of the noneliminated iron between its various chemical forms. Some of these transformations are influenced by the rhizosphere.

The present study shows that the coupling between the ammonia enriched environment and the rice roots was correct in the plain when in the lowland, things occurred as if rice roots were unable to provide the carbon for ammonia assimilation. Becker and Asch (2005) noted that in paddy soils producing high concentrations of ferrous ion, the roots may partly avoid iron uptake by oxidizing the proximate environment 
(formation of iron plaques around rice roots). In our case, it is possible that a large part of the photosynthates was dedicated to this mechanism, allowing insufficient carbon for ammonia assimilation. This could explain the weak response of transplanted rice in the lowland situations. In the plain, the response of rice to fertilizer is correct. Moreover, it is possible to increase the yield with increased PK application and split application of USG (Gaudin, 2012). The influence of $P$ was already demonstrated by Rabeharisoa et al. (2012).

\section{Conclusion}

Comparing lowland situations and plain situation, we found that transplanted rice fertilized with deep-placed urea supergranules did not uptake ammonia at the same rate. Ammonia was badly assimilated in the lowland. In the plain, ammonia was correctly assimilated and the grain yield difference with control was very significant. This dual response shows that the paddy soils are complex, with interaction between hydrological factors and parental material of the soil. Progress can be made by a better coordination of drainage in lowland fields during the dry season: it should permit counter-season crops such as potatoes or leguminous crops and it should place these fields in a better trajectory to avoid ferrous ion toxicity in the following wet season.

\section{COMPETING INTERESTS}

The authors declare they have no competing interests.

\section{AUTHORS' CONTRIBUTIONS}

RG supervised manuscript preparation and contributed to data collection and analysis. LR contributed to fields' selection and data collection. BR contributed to soil solution sampling and analysis.

\section{ACKNOWLEDGEMENTS}

The authors thank Samuel Randrianarison for monitoring soil solution extraction in the fields.

\section{REFERENCES}

Balasubramanian V, Rabeson R, Razafinjara L, Ratsimandresy J. 1995. Rice soil constraints and fertility management in the highlands of Madagascar, in Fragile lives in fragile ecosystems. In: Proceedings of the International Rice Research Institute, Manila, Philippines, 13-17 Feb 1995, pp 313-324.

Becker M, Asch F. 2005. Iron toxicity in riceconditions and management concepts. Journal of Plant Nutrition and Soil Science, 168: 558-573. DOI: 10.1002/jpln.200520504

Douglas LA, Bremner JM. 1970. Colorimetric determination of microgram quantities of urea. Analytical Letters, 3(2): 79-87.

Dupuy J, D’Onofrio G, Gaudin R. 1990. Etude à l'aide d'urée enrichie en $15 \mathrm{~N}$ de la fertilisation du riz inondé à Madagascar. I- Comparaison entre supergranules d'urée, perlurée et solution d'urée placés à $1 \mathrm{~cm}$ ou $10 \mathrm{~cm}$ de profondeur. L'Agronomie Tropicale, 45(1): 3-10.

Fageria NK, Santos AB, Barbosa Filho MP, Guimaraes CM. 2008. Iron toxicity in lowland rice. Journal of Plant Nutrition, 31:1676-1697.

DOI: 10.1080/01904160802244902

Gaudin R, Dupuy J. 1999. Ammoniacal nutrition of transplanted rice fertilized with large urea granules. Agronomy Journal, 91: 33-36.

Gaudin R. 2012. The kinetics of ammonia disappearance from deep-placed urea supergranules (USG) in transplanted rice: The effects of split USG application and PK fertiliser. Paddy and Water Environment, 10: 1-5. DOI: 10.1007/s10333-011-0249-3

Gaudin R, D'Onofrio G. 2015. Is the sourcesink relationship in transplanted rice receiving deep-placed urea supergranules dependent upon the geometry of transplanting? Paddy and Water Environment, 13: 433-442. DOI: 10.1007/s10333-014-0461-z 
Little TM, Hills FJ. 1978. Agricultural Experimentation. Design and Analysis. John Wiley and Sons: New York.

Minten B, Barrett CB. 2008. Agricultural technology, productivity, and poverty in Madagascar. World Development, 36(5): 797-822.

DOI:

10.1016/j.worlddev.2007.05.004

Novozamsky I, Van Eck R, Van Schouwenburg J, Walinga I. 1974. Total nitrogen determination in plant material by means of the indophenol-blue method. Netherlands Journal of Agricultural Science, 22: 3-5.

Rabeharisoa L, Razanakoto OR, Razafimanantsoa MP, Rakotoson T, Amery F, Smolders E. 2012. Larger bioavailability of soil phosphorus for irrigated rice compared with rainfed rice in Madagascar: results from a soil and plant survey. Soil Use and Management,
28(4): 448-456. DOI: 10.1111/j.14752743.2012.00444.x

Randrianja S, Ellis S. 2009. Madagascar. A Short History. The University of Chicago Press; $272 \mathrm{p}$.

Touré A, Becker M, Johnson DE, Koné B, Kossou DK, Kiepe P. 2009. Response of lowland rice to agronomic management under different hydrological regimes in an inland valley of Ivory Coast. Field Crops Research, 114: 304-310. DOI: 10.1016/j.fcr.2009.08.015

Tsujimoto $\mathrm{Y}$, Horie $\mathrm{T}$, Randriamihary $\mathrm{H}$, Shiraiwa T, Homma K. 2009. Soil management: The key factors for higher productivity in the fields utilizing the system of rice intensification (SRI) in the central highland of Madagascar. Agricultural Systems, 100: 61-71. DOI: 10.1016/j.agsy.2009.01.001 